\title{
Delayed Cerebral Abnormalities in Acute Hyperammonemic Encephalopathy
}

\author{
Hiroshi Ito ${ }^{1}$, Yasuhiro Ogawa ${ }^{1}$, Nobutake Shimojo ${ }^{1}$, Satoru Kawano ${ }^{1}$ \\ 1. Division of Hospital Medicine, University of Tsukuba Hospital, Tsukuba, JPN
}

Corresponding author: Hiroshi Ito, itohirokan@yahoo.co.jp

\begin{abstract}
Acute hyperammonemic encephalopathy (AHE) is a rare but life-threatening condition. We present a case of an 81-year-old woman with cirrhotic AHE who presented with prolonged disorientation. Her magnetic resonance (MR) images were normal on the third hospital day, which showed bilateral abnormalities in the insular and cingulate cortices on day 13 . The imaging abnormalities were slightly improved but remained on day 24. The imaging abnormalities seemed correlated with her persistent disorientation. AHE can present as delayed cerebral abnormalities, and follow-up imaging tests are useful in detecting such conditions. Further reports are needed to investigate the correlation between imaging abnormalities and clinical outcomes in patients with AHE.
\end{abstract}

Categories: Endocrinology/Diabetes/Metabolism, Emergency Medicine, Gastroenterology Keywords: acute hyperammonemic encephalopathy, cirrhosis

\section{Introduction}

Patients with acute hyperammonemic encephalopathy (AHE) present with impaired consciousness, seizures, and death due to the toxic effect of ammonia on the brain [1]. AHE can be caused by hepatic disorders, urea cycle disorders, and drugs, including antiepileptics [2].

The typical radiologic findings of AHE have been known as four different types: diffuse cerebral edema, extensive infarct-like abnormalities, ischemic lesions, and symmetric cortical involvement [3]. However, little is known about the time course of changes in imaging findings of AHE.

Here we describe a patient with cirrhotic AHE who presented with persistent disorientation. Her magnetic resonance (MR) images of the brain were normal on admission, which later showed bilateral cortical abnormalities.

Received 09/02/2020 Review began 09/05/2020 Review ended 09/05/2020 Published 09/08/2020

(๑) Copyright 2020

Ito et al. This is an open access article distributed under the terms of the Creative Commons Attribution License CC-BY 4.0., which permits unrestricted use, distribution, and reproduction in any medium, provided the original author and source are credited.

\section{Case Presentation}

An 81-year-old Japanese woman with hepatitis B virus-related cirrhosis admitted to our hospital because of impaired consciousness. Her heart rate was 103 beats per minute, blood pressure 154/72 $\mathrm{mmHg}$, temperature $98^{\circ} \mathrm{F}$, and respiratory rate 16 per minute. Neurological examination did not reveal neck rigidity and abnormal deep tendon reflexes. She was suspected of having hepatic encephalopathy because of asterixis and received branched-chain amino acids and lactulose. The plasma ammonia level was $322 \mu \mathrm{g} / \mathrm{dL}$ as seen in Table 1 , and cerebrospinal fluid polymerase chain reaction for herpes simplex virus was negative. 


\section{Cureus}

\begin{tabular}{|c|c|c|c|c|c|c|c|c|c|c|}
\hline & Day 1 & Day 2 & Day 3 & Day 4 & Day 5 & Day 10 & Day 15 & Day 23 & Day 41 & Day 51 \\
\hline White blood cell $(/ \mu L)$ & 11,100 & 17,000 & 20,500 & 17,300 & 16,800 & 7,700 & 8,600 & 7,800 & 8,000 & 6,600 \\
\hline Hemoglobin (g/dL) & 7.2 & 6.6 & 9.7 & 8.6 & 8 & 8.3 & 8.8 & 8.7 & 7.8 & 8.4 \\
\hline Platelet (x104/LL) & 21.6 & 24.4 & 23.6 & 18.8 & 11.7 & 9.9 & 12.9 & 9.1 & 10.4 & 10.7 \\
\hline Asparete aminotransferase (U/L) & 22 & 30 & 29 & 73 & 95 & 132 & 70 & 38 & 28 & 37 \\
\hline Alanine aminotransferase (U/L) & 12 & 12 & 13 & 26 & 81 & 133 & 102 & 41 & 17 & 15 \\
\hline Lactate dehydrogenase (U/L) & 302 & 383 & 494 & 622 & 456 & 468 & 553 & 632 & 411 & 446 \\
\hline Alkaline phosphatase (U/L) & 189 & & 185 & 152 & 174 & 741 & 739 & 595 & & \\
\hline$\gamma$-glutamyl transferase $(\mathrm{U} / \mathrm{L})$ & 40 & 37 & 35 & 41 & 60 & 378 & 321 & 226 & 122 & \\
\hline Sodium (mEq/L) & 140 & 142 & 148 & 150 & 161 & 146 & 153 & 155 & 147 & 150 \\
\hline Chlorine (mEq/L) & 98 & 101 & 106 & 114 & 129 & 115 & 118 & 121 & 110 & 112 \\
\hline Pottasium (mEq/L) & 2.8 & 3.1 & 3 & 4 & 3.6 & 3.8 & 3.1 & 4 & 4.2 & 4.9 \\
\hline Urea nitrogen $(\mathrm{mg} / \mathrm{dL})$ & 80.1 & 93.3 & 131.1 & 153.1 & 125.6 & 32.3 & 42.2 & 31.5 & 40 & 30.5 \\
\hline Creatinine (mg/dL) & 0.95 & 1.22 & 1.92 & 1.81 & 1.15 & 0.94 & 0.81 & 0.81 & 0.73 & 0.66 \\
\hline Ammonia ( $\mu \mathrm{g} / \mathrm{dL})$ & & 322 & 417 & 214 & 115 & 54 & 42 & & 57 & \\
\hline C-reactive protein (mg/dL) & 2.2 & 2.24 & 3.32 & 4.63 & 3.94 & 1.8 & 2.91 & 0.97 & 3.21 & 1.84 \\
\hline
\end{tabular}

\section{TABLE 1: Laboratory data of the blood samples}

Serum ammonia reached its peak on the third hospital day, and decreased gradually.

Initial MR images of the brain showed no remarkable changes (Figure $1 \mathrm{~A}$ ). Electroencephalogram revealed triphasic waves.

She developed status epilepticus and was intubated on the third hospital day. MR images on day 11 showed symmetric abnormal signal intensity in the insular and cingulate cortices bilaterally, which suggested the toxic effect of accumulated ammonia (Figure 1B).

Her consciousness improved slightly after extubation on day 13, when the plasma ammonia level was 32 $\mu \mathrm{g} / \mathrm{dL}$. The abnormal signal intensity on the brain MR images partially improved on day 24 , but her disorientation remained (Figure 1C). She was transferred to a long-stay hospital to continue rehabilitation on day 52 . 


\section{Cureus}

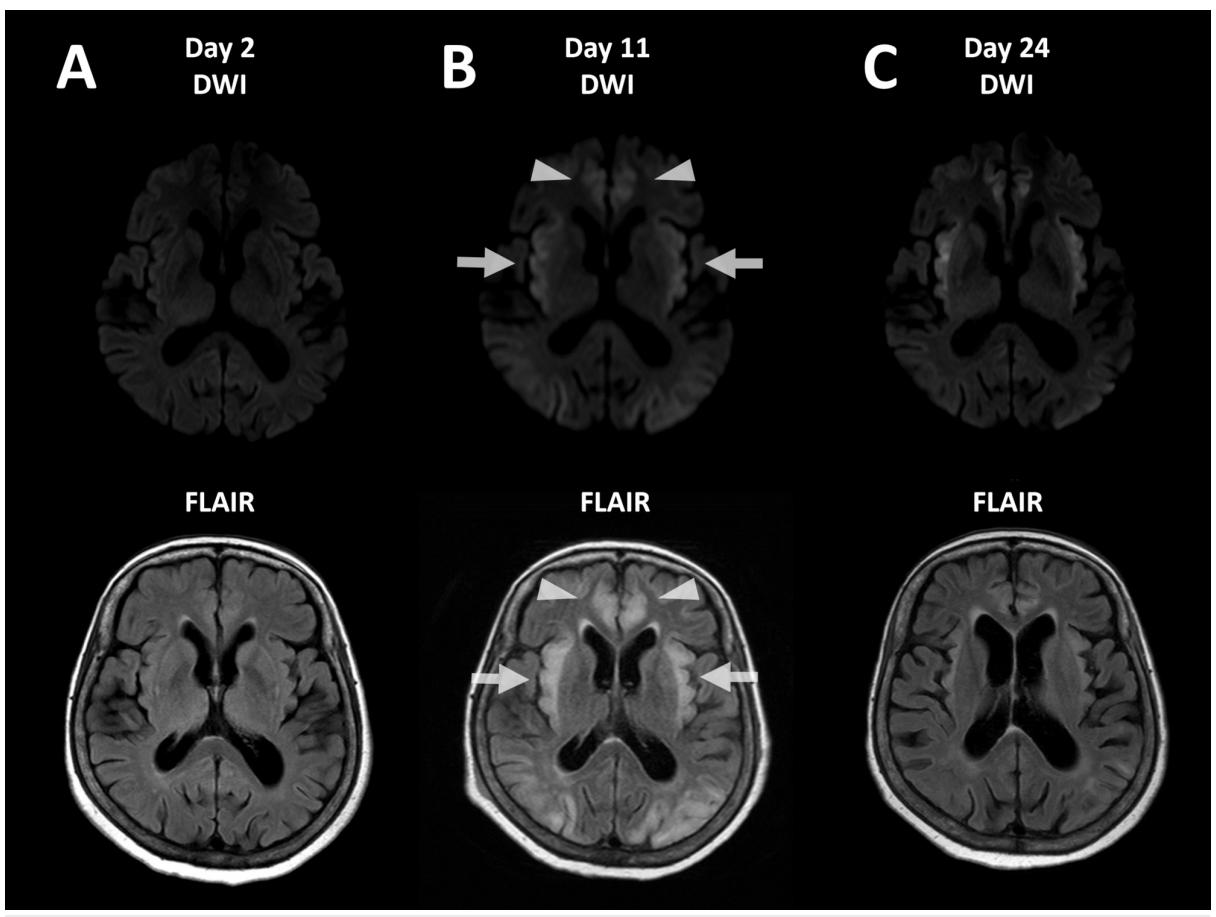

FIGURE 1: MR images of the brain

(A) Initial MR images of the brain showing no remarkable changes. (B) MR images on day 11 showing symmetric abnormal signal intensity in the insular (arrows) and cingulate cortices (arrowheads) on diffusionweighted imaging (DWI) and fluid-attenuated inversion recovery (FLAIR) imaging sequences. (C) MR images on day 24 showing improvement of the abnormal signal intensity.

\section{Discussion}

We found out two important clinical issues. AHE can present as delayed cerebral abnormalities. Follow-up MR imaging is useful for the diagnosis of this condition.

First, AHE can present as late-onset abnormalities of the brain. Previous reports have described various radiographic findings of AHE (Table 2). 


\section{Cureus}

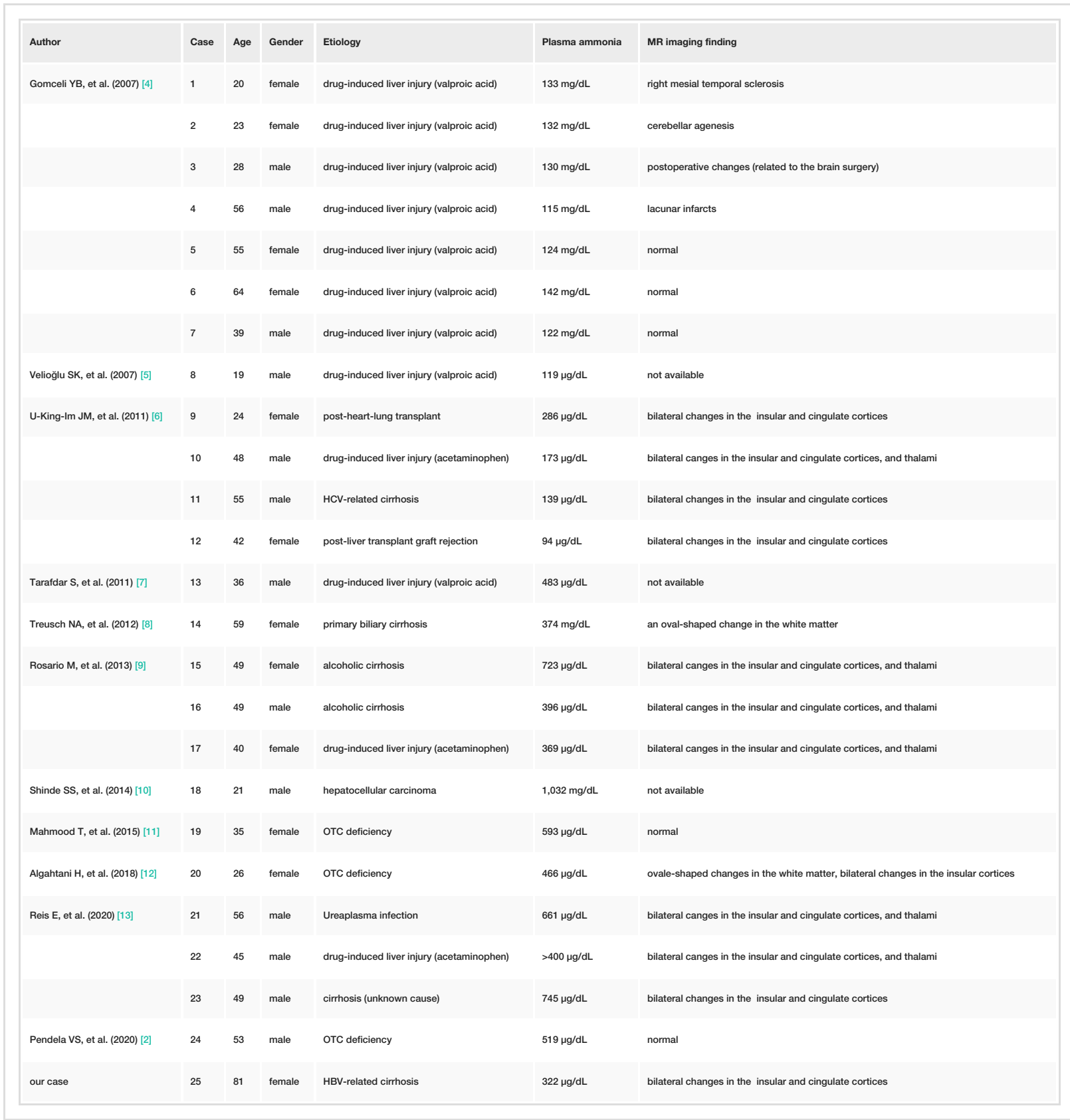

\section{TABLE 2: Previous reports on hyperammonemic encephalopathy}

MR- magnetic resonance, $\mathrm{HCV}$ - hepatitis $\mathrm{C}$ virus, OTC- ornithine transcarbamylase, HBV- hepatitis B virus

The mechanism of these findings has not been fully elucidated, but a major hypothesis is that glutamine produced from ammonia causes swelling of astrocytes, resulting in brain edema. Other hypotheses include the production of the neurotoxin alpha-ketoglutaramate [14]. However, several reports have described AHE patients whose radiographic findings of the brain were within normal limits. These patients might have presented with delayed cerebral edema if they had undergone follow-up imaging tests.

Second, follow-up MR imaging is useful in detecting late-onset cerebral abnormalities. Our patient showed prolonged MR imaging abnormalities, which seemed correlated with her persistent disorientation. Treusch and colleagues described a woman with HAE who became asymptomatic two weeks after onset when her MR images also became normal [8]. Although the relationship between abnormalities on MR images and neurological prognosis has not been investigated, follow-up MR imaging may be useful in predicting neurological recovery of HAE patients. The differential diagnosis of symmetric abnormal signal intensity in MR images includes posterior reversible encephalopathy syndrome, seizure activity, and diffuse hypoxicischemic injury [6]. 
The delayed imaging findings of diseases have well been described in other fields, which can be detected by follow-up imaging tests. For example, it has been known that patients with early pneumonia may not present with significant findings on chest radiographs [15]. Follow-up chest radiography is useful in diagnosing pneumonia in some of these patients [16]. Imaging tests should, if possible, be evaluated more than once to assess the state of diseases over time.

\section{Conclusions}

AHE can present as delayed cerebral abnormalities, and follow-up MR imaging is useful for the diagnosis of this condition. These abnormalities can be revealed in MR images several days after the serum ammonia level reaches its peak, and can be missed without follow-up imaging tests. Further reports should be accumulated to determine whether "hidden" AHE may be much more frequently present and whether follow-up imaging tests may contribute to picking up AHE patients with poor clinical outcomes.

\section{Additional Information \\ Disclosures}

Human subjects: Consent was obtained by all participants in this study. Conflicts of interest: In compliance with the ICMJE uniform disclosure form, all authors declare the following: Payment/services info: All authors have declared that no financial support was received from any organization for the submitted work. Financial relationships: All authors have declared that they have no financial relationships at present or within the previous three years with any organizations that might have an interest in the submitted work. Other relationships: All authors have declared that there are no other relationships or activities that could appear to have influenced the submitted work.

\section{References}

1. Clay AS, Hainline BE: Hyperammonemia in the ICU. Chest. 2007, 132:1368-1378. 10.1378/chest.06-2940

2. Pendela VS, Kudaravalli P, Munoz A, Razzouk G: A mysterious case of recurrent acute hyperammonemic encephalopathy. Cureus. 2020, 12:e7484. 10.7759/cureus.7484

3. Takanashi J, Barkovich AJ, Cheng SF, Kostiner D, Baker JC, Packman S: Brain MR imaging in acute hyperammonemic encephalopathy arising from late-onset ornithine transcarbamylase deficiency. AJNR Am J Neuroradiol. 2003, 24:390-393.

4. Gomceli YB, Kutlu G, Cavdar L, Sanivar F, Inan LE: Different clinical manifestations of hyperammonemic encephalopathy. Epilepsy Behav. 2007, 10:583-587. 10.1016/j.yebeh.2007.02.013

5. Velioğlu SK, Gazioğlu S: Non-convulsive status epilepticus secondary to valproic acid-induced hyperammonemic encephalopathy. Acta Neurol Scand. 2007, 116:128-132. 10.1111/j.16000404.2006.00793.x

6. U-King-Im JM, Yu E, Bartlett E, Soobrah R, Kucharczyk W: Acute hyperammonemic encephalopathy in adults: imaging findings. AJNR Am J Neuroradiol. 2011, 32:413-418. 10.3174/ajnr.A2290

7. Tarafdar S, Slee M, Ameer F, Doogue M: A case of valproate induced hyperammonemic encephalopathy . Case Rep Med. 2011, 969505. 10.1155/2011/969505

8. Treusch NA, van de Loo S, Hattingen E: Reversible laminar signal intensity in deep cortical gray matter in T1-weighted images and FLAIR after mild acute hyperammonemic hepatic encephalopathy. J Neuroradiol. 2012, 39:350-353. 10.1016/j.neurad.2012.03.002

9. Rosario M, McMahon K, Finelli PF: Diffusion-weighted imaging in acute hyperammonemic encephalopathy . Neurohospitalist. 2013, 3:125-130. 10.1177/1941874412467806

10. Shinde SS, Sharma P, Davis MP: Acute hyperammonemic encephalopathy in a non-cirrhotic patient with hepatocellular carcinoma reversed by arginine therapy. J Pain Symptom Manage. 2014, 47:E5-E7. 10.1016/j.jpainsymman.2014.01.002

11. Mahmood T, Nugent K: Nonhepatic hyperammonemic encephalopathy due to undiagnosed urea cycle disorder. Proc (Bayl Univ Med Cent). 2015, 28:375-377. 10.1080/08998280.2015.11929281

12. Algahtani H, Alameer S, Marzouk Y, Shirah B: Urea cycle disorder misdiagnosed as multiple sclerosis: a case report and review of the literature. Neuroradiol J. 2018, 31:213-217. 10.1177/1971400917715880

13. Reis E, Coolen T, Lolli V: MRI findings in acute hyperammonemic encephalopathy: three cases of different etiologies. J Belg Soc Radiol. 2020, 104:9. 10.5334/jbsr.2017

14. Butterworth RF: Pathophysiology of brain dysfunction in hyperammonemic syndromes: the many faces of glutamine. Mol Genet Metab. 2014, 113:113-117. 10.1016/j.ymgme.2014.06.003

15. Basi SK, Marrie TJ, Huang JQ, Majumdar SR: Patients admitted to hospital with suspected pneumonia and normal chest radiographs: epidemiology, microbiology, and outcomes. Am J Med. 2004, 117:305-311. 10.1016/j.amjmed.2004.03.029

16. Hagaman JT, Rouan GW, Shipley RT, Panos RJ: Admission chest radiograph lacks sensitivity in the diagnosis of community-acquired pneumonia. Am J Med Sci. 2009, 337:236-240. 10.1097/MAJ.0b013e31818ad805 